\section{Discussion}

Although there has been extensive investigation of the various effects of alcohol in man, no studies of the effect of alcohol on gastrointestinal blood loss have been published.

In the present investigation gastrointestinal blood loss after ingestion of alcohol did not differ from that during the control period in the seven subjects studied (Table II). Leonards (personal communication, 1968) has also been unable to produce gastrointestinal bleeding in normal subjects after ingestion of alcohol. It is possible, however, that the concentration of alcohol in contact with gastric mucosa may be a critical factor.

In the present study alcohol when given alone did not cause gastrointestinal bleeding, but in the same dosage it increased aspirin-induced gastrointestinal blood loss (Table I). Gastrointestinal blood loss induced by unbuffered aspirin is variable from individual to individual, but Croft and Wood (1967) found that the bleeding response of each individual subject was reproducible. They studied gastrointestinal bleeding due to aspirin ingestion in 21 subjects on two occasion 3 and found the mean daily faecal blood loss to be 6.3 and $6.5 \mathrm{ml}$. Thus in the present study the statistically significant increase in gastrointestinal blood loss associated with ingestion of alcohol plus aspirin was almost certainly due to the addition of alcohol and not to variation in bleeding in response to aspirin alone.
The mechanism of action of alcohol on gastrointestinal blood loss induced by aspirin was not studied in the present experiments. Davenport (1965) found that in dogs with a Heidenhain pouch aspirin caused bleeding from the pouch only if the $\mathrm{pH}$ of the contents was acid. As alcohol is a known stimulant of gastric acid secretion it is possible that the increased bleeding with alcohol plus aspirin was a result of lowered $\mathrm{pH}$ of the gastric contents during the period aspirin was in the stomach.

We are grateful to Miss Angela Birchall and Miss Irena Lopata for technical assistance, to the subjects for their co-operation, and to Mr. David Paix, physicist, Prince Henry Hospital, for advice and for the use of the ARMAC counter. One of us (K. G.) was supported by an Abbott Fellowship of the Royal Australasian College of Physicians, and another (A. R. C.) by the National Health and Medical Research Council, Australia. This work was supported in part by the Bushell Trust.

\section{REFERENCES}

Croft, D. N., and Wood, P. H. N. (1967). Brit. med. 7., 1, 137. Davenport, H. W. (1965). Gastroenterology, 49, 189. Goulston, K., and Skyring, A. (1964). Gut, 5, 463. Smith, M J H., and Smith, P. K. (1966). The Salicylates. New York. Snedecor, G. W., and Cochran, W. G. (1967). Statistical Methods, 6th
ed. Ames, Iowa.

\title{
Serum Fibrin Degradation Products throughout Normal Pregnancy
}

\author{
D. G. WOODFIELD,* M.B., M.R.C.P.ED. ; S. K. COLE, $†$ M.B., M.R.C.o.G. ; A. G. E. ALLAN, $\ddagger$ F.I.M.L.T. \\ J. D. CASH,§ M.B., PH.D., M.R.C.P.ED.
}

Brit. med.7., 1968, ৎ, 665-668

\begin{abstract}
Summary : Fibrin/fibrinogen degradation products in the serum of 169 healthy pregnant and 43 healthy non-pregnant subjects of a similar age group showed a significant increase throughout pregnancy, the highest levels being obtained in the third trimester. There was no correlation with plasma fibrinogen levels or euglobulin lysis times. Though these changes may be due to other alterations in pregnancy not primarily associated with fibrinolysis, it is possible that actual fibrinolysis is not decreased in late pregnancy, as has been previously asssumed.
\end{abstract}

\section{Introduction}

The human fibrinolytic enzyme system in normal pregnancy has been studied extensively in the past decade. Most investigators are now agreed that those methods considered to assess the level of circulating plasminogen activator will readily show a marked diminution of this enzyme in the latter part of the gestational period (Biezenski and Moore, 1958; Gillman et al., 1959 ; Biezenski, 1960 ; Shaper et al., 1965; Nilsson and Kullander, 1967). Furthermore, other groups have confirmed the earlier findings of Brakman and Astrup (1963) that the plasma urokinase inhibitor activity is increased in the third trimester of pregnancy (Kawano et al., 1968; Shaper et al.,

* Registrar.

+ Registrar, Simpson Memorial Maternity Pavilion, Royal Infirmary, Edinburgh 3.

¥ Senior Technician.

Deputy Director.

outh-east Scotland Regional Blood Transfusion Centre, Royal Infirmary, Edinburgh 3.
1968). Moreover, Brakman (1966) has presented evidence which indicates that the binding of the plasminogen activatorcomplex, envisaged by Olesen (1961), is also increased in the third trimester.

Plasminogen activators are believed to play a key part in promoting in-vivo fibrinolysis (Fearnley, 1953 ; Sherry et al., 1959), whereas fibrinolytic inhibitors retard this process (Naeye, 1961 ; Nilsson et al., 1961 ; Turpie et al., 1967). In the light of the evidence currently available it would therefore be reasonable to assume that the actual lysis of fibrin in the latter months of pregnancy is in fact depressed. Proof of this is lacking, however, for the methods used to accumulate this evidence have assessed only the absolute circulating levels of the various fibrinolytic components and have provided relatively little information on their in-vivo dynamic interactions.

The recent introduction of the tanned red-cell haemagglutination inhibition immunoassay for the quantitative assessment of circulating fibrin/fibrinogen degradation products (F.D.P.) (Murakami, 1965; Merskey et al., 1966) and its subsequent development to enable the detection of F.D.P. levels in over $95 \%$ of normal sera (Das et al., 1967) now allows a further investigation of the fibrinolytic enzyme system in pregnancy, for it can be assumed that the level of serum F.D.P. represents a measure of active in-vivo fibrinolysis.

The following communication describes the results of an investigation designed to ascertain the level of serum F.D.P. in 169 normal pregnant women in order to test the hypothesis discussed above and to provide normal values as guide lines for the diagnosis of those haemorrhagic emergencies which occasionally complicate pregnancy. 


\section{Subjects}

Blood samples were obtained from 169 pregnant women (mean age $24 \pm 5$ years) attending routine antenatal clinics of the Simpson Memorial Maternity Pavilion. The patients were grouped so as to have approximately equal numbers in each trimester. At the time of blood withdrawal they were considered to have entirely normal pregnancies, and in particular there was no clinical evidence of pre-eclamptic toxaemia. Forty-three healthy non-pregnant women of a similar age group, receiving no form of medication, were used as controls.

\section{Material and Methods}

\section{Blood Sampling and Processing}

From each patient and control, $5 \mathrm{ml}$. of cubital venous blood was withdrawn, with the minimum of venous occlusion, into a plastic syringe and transferred to $0.1 \mathrm{ml}$. of aprotinin (Trasylol) $(5,000$ units $/ \mathrm{ml}$.) in a glass test-tube. The specimen was then incubated at $37^{\circ} \mathrm{C}$. for four hours, the serum being separated and stored in aliquots in plastic tubes at $-40^{\circ} \mathrm{C}$. Each tube had a code number, and those responsible for the assays were unaware of the clinical details.

In a number of the patients citrated $(4.5 \mathrm{ml}$. blood in $0.5 \mathrm{ml} .3 .8 \%$ sodium citrate B.P.) and aprotinin-citrated $(4.5 \mathrm{ml}$. blood in $0.5 \mathrm{ml} .3 .8 \%$ sodium citrate plus $0.1 \mathrm{ml}$. aprotinin, 5,000 units $/ \mathrm{ml}$.) samples were collected for euglobulin lysis times and fibrinogen assays respectively. Plasma was obtained from these specimens after centrifugation at 3,200 r.p.m. for 20 minutes at $4^{\circ}$ C. Euglobulin lysis time estimations were performed immediately, whereas piasma for fibrinogen estimations was stored in aliquots at $-40^{\circ}$ C. until assayed.

\section{Serum F.D.P. Assay}

The assay method of Merskey et al. (1966) was used with the following modifications.

(a) After thawing the test serum, $1 / 10$ of its volume of thrombin was added (100 units/ml. in saline), the mixture being incubated at $37^{\circ} \mathrm{C}$. for one hour and then centrifuged at 3,400 r.p.m. for 10 minutes. This procedure removed any residual fibrinogen.

(b) All serum samples were absorbed overnight at $4^{\circ} \mathrm{C}$. with one volume of saline-washed normal sheep red cells to two volumes of test serum and either assayed immediately or stored at $-40^{\circ} \mathrm{C}$.

(c) The immunoassay was performed in the microtitre system (Cooke Engineering Co.), and all reagents, including fibrinogen standards and sensitized cells, were from the same batch.

(d) Three concentrations of human fibrinogen (Kabi Pharmaceuticals Ltd.) were included in each daily run. The concentration of clottable protein in these standards was estimated on numerous occasions by the method of Ratnoff and Menzie (1951) as modified by Alkjaersig $(1960)$ and the mean values were calculated. Based on these values, the mean sensitivity of the immunoassay after 29 separate runs was $0.5 \pm 0.15 \mu \mathrm{g} . / \mathrm{ml}$. A standard absorbed normal serum was also incorporated into each run as a further control, the mean value of which was $6.4 \pm 1.5 \mu \mathrm{g} . / \mathrm{ml}$. after 20 separate estimations.

(e) Each test serum was assayed at two concentrations of antisera $(1 / 5,000$ and $1 / 10,000$; Hoechst Pharmaceuticals Ltd., batch No. 1202M), and a system of double doubling dilutions of test serum, beginning at $1 / 2$ and $1 / 3$, was used in all assays.

(f) Twenty-four samples were assayed on most runs, each batch consisting of about equal numbers of controls and pregnancy samples, chosen at random. (g) The antigen-antibody incubation period was 24 hours at $4^{\circ} \mathrm{C}$., as was the period following the addition of the sensitized sheep red cells.

(h) After the microtitre plates had been at room temperature for 30 minutes they were read by the same observer for the whole project, who was unaware of the source of each specimen.

(i) All serum samples with an F.D.P. value above $20 \mu \mathrm{g} . / \mathrm{ml}$. were reassayed. There was satisfactory reproducibility of results in all such specimens.

\section{Euglobulin Lysis Time}

The assays were performed as described previously (Cash, 1966). The clot lysis end-points were assessed on an automatic clot lysis time recorder (Cash and Leask, 1967).

\section{Fibrinogen Assay}

The fibrinogen content of the aprotinin-citrate plasma samples was measured by the method of Ellis and Stransky (1961). A known pooled plasma was used as a control in each group of specimens assayed.

\section{Results}

The results of the serum F.D.P. values in 169 pregnant women and 43 non-pregnant controls are shown in the Chart and summarized in the Table. There was a progressive rise

Results of F.D.P. Estimations in 169 Pregnant and 43 Non-pregnant Subjects

\begin{tabular}{l|c|c|c|c}
\hline & $\begin{array}{c}\text { Control } \\
\text { Group } \\
\text { (Non-preg- } \\
\text { nant) }\end{array}$ & \multicolumn{3}{|c}{ Pregnant Group } \\
\cline { 3 - 5 } & $\begin{array}{c}\text { 1st } \\
\text { Trimester }\end{array}$ & $\begin{array}{c}\text { 2nd } \\
\text { Trimester }\end{array}$ & $\begin{array}{c}\text { 3rd } \\
\text { Trimester }\end{array}$ \\
\hline $\begin{array}{l}\text { Mean F.D.P. level ( } \mu \mathrm{g} . / \mathrm{ml} .) \\
\text { No. of subjects }\end{array}$ & $\begin{array}{c}6 \cdot 5 \pm 2 \cdot 1 \\
43\end{array}$ & $\begin{array}{c}6 \cdot 6 \pm 2 \cdot 6 \\
53\end{array}$ & $\begin{array}{c}8 \cdot 2 \pm 4 \cdot 1 \\
57\end{array}$ & $\begin{array}{c}14 \cdot 0 \pm 6.9 \\
59\end{array}$ \\
\hline
\end{tabular}

in the mean value throughout pregnancy. Statistical analysis, by Student's $t$ test, showed a significantly higher mean concentration in the second and third trimesters compared with the controls $(t=2.567,0.01<\mathrm{P}<0.02$, and $t=6.931, \mathrm{P}<0.001$, respectively). There was also a significantly higher mean value in the second compared with the first trimester $(t=2.544$, $0.01<\mathrm{P}<0.02)$ and in the third compared with the second trimester $(t=5.449, \mathrm{P}<0.001)$. However, there was no correlation between the euglobulin lysis times and the F.D.P. values $(r=0.1085, P=N . S$. $)$ in the 36 patients studied, nor between

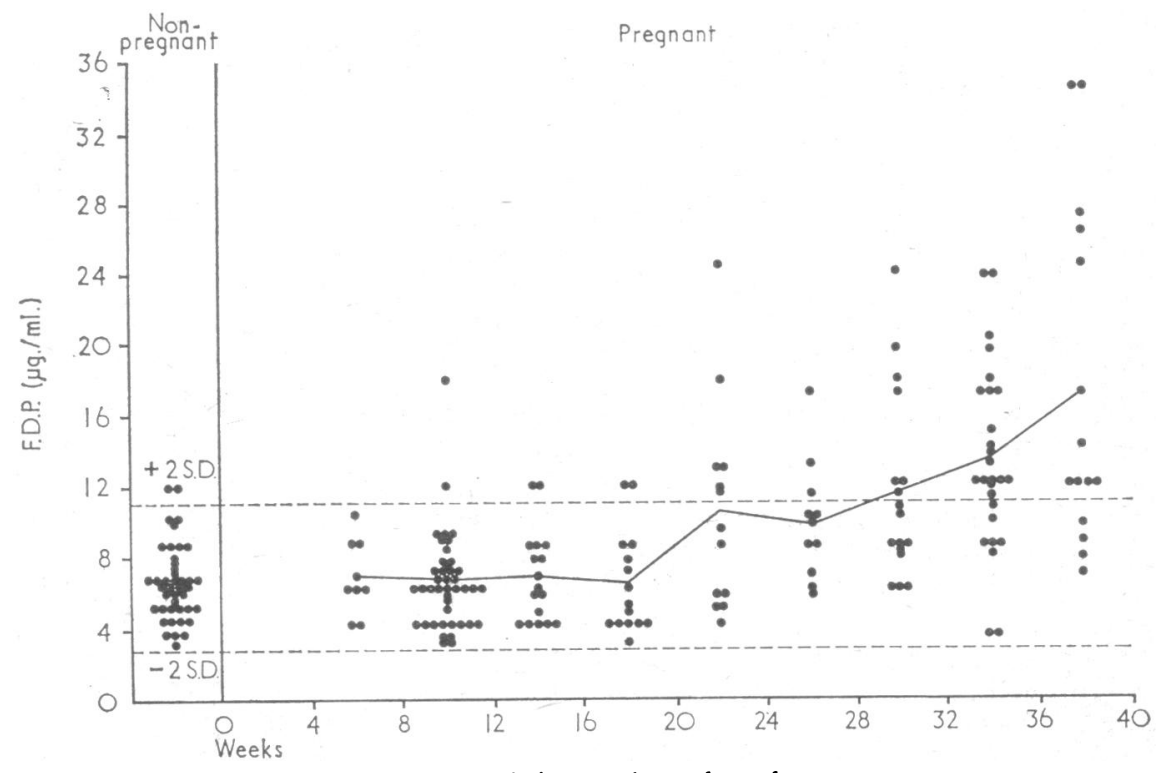

Fibrin/fibrinogen degradation products throughout pregnancy. 
the plasma fibrinogen and serum F.D.P. levels in 48 of the patients $(r=0.0516, P=N . S$.).

When the antenatal records of the subjects were reviewed there was no apparent correlation between parity, the incidence or forms of subsequent obstetrical complications, and the levels of serum F.D.P.

\section{Discussion}

The absence of a correlation between the levels of serum F.D.P. and plasma fibrinogen in the pregnant group as a whole, and in any one trimester, suggests that the observation of a highly significant increase in serum F.D.P. in the latter months of pregnancy is unlikely to be an artifact due to unclotted fibrinogen but a true reflection of the level of these circulating immunologically reactive polypeptides.

One interpretation of these findings is that, despite the low and high absolute concentrations of circulating plasminogen activator and fibrinolytic inhibitors respectively, the level of generalized in-vivo fibrinolysis is in fact increased in the second half of pregnancy. Such an interpretation would lend support to the view that the absolute concentration of certain fibrinolytic factors may provide only partial information on their dynamic interreactions in vivo. It is possible that the low levels of plasminogen activator are reflecting an increased consumption of this enzyme-subsequent to increased intravascular coagulation-which is not readily being replaced. It is also possible that the progressive fall in circulating platelets in pregnancy (Shaper et al., 1968) might be due to increased intravascular coagulation, but no fibrinogen turnover studies in normal pregnancy have yet been reported. There is some evidence, however, that there may be an inability to replace plasminogen activator rapidly in late pregnancy, for we have reported that the mechanism for generating circulating plasminogen activator to a standard exercise stress in normal pregnant women at term is frequently impaired (Woodfield et al., 1968).

While it is tempting to conclude that the interpretation of these results must await further advances in our understanding of the mechanisms of in-vivo fibrinolysis, it seems probable that the real explanation(s) may be found in other changes in pregnancy which are not primarily associated with fibrinolysis. For example, if fibrin deposition and its removal is a normal process on the intimal surface of all blood vessels (Astrup, 1956), then the increase in the "active intimal surface area" subsequent to the vasodilatation in late pregnancy (Winner, 1965 ; Ginsburg and Duncan, 1967) may be the site from which an additional load of F.D.P. arises. Similarly, venous obstruction of the lower limbs occurs in normal pregnancy, so that the femoral vein pressure gradually increases after the twentieth week (McLennan, 1943 ; Wright et al., 1950). Acute venous occlusion increases the serum F.D.P. concentration in the distal vessels (Niléhn and Nilsson, 1964), and it is possible that this factor could play a part in the observed increase in circulating F.D.P. in late pregnancy.

Exercise has been shown to increase circulating F.D.P. (Das et al., 1967), and it might be assumed that the increased energy expenditure involved in attending the antenatal clinic in the later months of pregnancy could have played a part in the primary observation of this study. However, there is no evidence that a fixed exercise procedure demands a higher energy expenditure in late pregnancy (Seitchik, 1967), and recent unpublished observations undertaken in this laboratory have not shown a significant rise in serum F.D.P. following moderate exercise.

During pregnancy there, is a marked increase in maternal weight, a high proportion of which is due to changes in the uterus and its contents, and enlargement of breasts (Hytten and Leitch, 1964). Mackay et al. (1964) showed a positive arteriovenous difference in serum F.D.P. across the nonpregnant uterus. If the F.D.P. leaving the uterus is related to the blood flow of this organ then the reported increase from less than $100 \mathrm{ml} . / \mathrm{min}$. in the first trimester to $700-800 \mathrm{ml} . / \mathrm{min}$. at term (Metcalfe et al., 1955 ; Assali et al., 1960 ; Huckabee, 1962) would suggest that the uterus itself may be the source of the increased level of circulating F.D.P. in late pregnancy.

In a series of ingenious experiments on pregnant golden hamsters, Brown and Stalker (1968) showed that following both spontaneous premature placental separation and the artificial application of trauma to the placenta-sufficient to cause retroplacental haematoma formation-white emboli resembling fibrin emboli are released from the placental bed into the maternal and foetal circulations. If the damage is severe enough the animals develop a characteristic defibrination syndrome. Devi et al. (1968) focused attention on the high incidence (64\%) at term in normal pregnancies of macroscopic placental lesions in the form of Kline's haemorrhages, intervillous thrombosis, placental infarction, and retroplacental haematoma. The presence of these lesions appeared to be associated with evidence of transplacental haemorrhage (foetal cells in the maternal circulation). Woodrow and Finn (1966) showed a linear increase in the incidence of foetal cells in the maternal circulation during the third trimester. In view of these observations, and of those of Brown and Stalker (1968), it seems probable that the increase in circulating F.D.P. in late pregnancy could be causally related to an increasing incidence of placental damage.

It is well known that the extravascular fluids contain fibrinogen (Gitlin et al., 1953) and that this may represent up to $50 \%$ of the total body content (Hammond and Verel, 1959; Lewis et al., 1961). Furthermore, Benz (1968) demonstrated the presence of both plasminogen activator and F.D.P. in extravascular fluids. We have emphasized previously the probable importance of an extravascular contribution to the circulating blood F.D.P. (Das et al., 1967), and it is conceivable that fibrinolysis in actively growing tissues, such as the uterus and breasts, may have contributed to our findings.

The mechanisms for the elimination of circulating F.D.P. have not yet been elucidated, though there are some data which suggest hepatic, reticuloendothelial (Gans and Lowman, 1967), and renal (Herschlein and Steichele, 1968) pathways. While there is no evidence to show that renal function (Chesley and Chesley, 1939 ; El-Mahallawi et al., 1968) or reticuloendothelial activity (McKay et al., 1964) is impaired during normal pregnancy, the finding of a progressive cholestasis and a small but significant impairment of mean hepatic excretory function with advancing pregnancy (Simcock and Forster, 1967) might be regarded as relevant. However, the recent observation of normal serum F.D.P. in some patients with uncompensated hepatic cirrhosis (Das and Cash, 1968) suggests that the changes of hepatic function in pregnancy are unlikely to be responsible for the increased level of serum F.D.P.

Although it is recognized that the cause of the raised levels of serum F.D.P. in late pregnancy is probably multifactorial, the assumption that in-vivo fibrinolysis is depressed during this period may prove to be unwarranted. However, much more information is required concerning the mechanisms controlling the production and clearance of these polypeptides, in terms of both anatomical sites and biochemical systems. Nevertheless, it is evident that these results are of considerable interest in furthering studies of those complications in pregnancy associated with excessive coagulation and fibrinolysis, and it is possible that one of the benefits of such investigations may be a better understanding of the basic mechanisms of in-vivo fibrinolysis, which at present eludes us.

We would like to thank Professor R. J. Kellar, Dr. G. D. Matthew, and Dr. W. D. A. Callum for allowing us to study patients in their care; Dr. R. A. Cumming for laboratory facilities and sustained encouragement ; Dr. P. C. Das, who was responsible for establishing the serum F.D.P. assay in this laboratory; and Miss Linda Goodger for excellent technical assistance. This research programme was supported by a grant from the Scottish Hospital Endowments Research Trust. 


\section{REFERENCES}

Alkjaersig, N. (19:-0). In Conference on Thrombolytic Agents, edited by H. R. Roberts and J. D. Geraty, p. 136. Chapel Hill.

Assali, N. S., Rauramo, L., and Peltonen, T. (1960). Amer. F. Obstet. Gynec, 79, 86.

Astrup, T. (1956). Lancet, 2, 565.

Benz, J. J. (1968). Thrombos. Diathes. haemorrh. (Stuttg.), 19, 226.

Biezenski, J. J. (1960). J. clin. Path., 13, 220.

Biezenski, J. J., and Moore, H. C. (1958). F. clin. Path., 11, 306.

Brakman, P. (1966). Amer. 7. Obstet. Gynec., 94, 14.

Brakman, P., and Astrup, $\mathrm{T}$ (1963). Scand. F. clin. Lab. Invest., 15,

Brakman, P., and Astrup, T. (1963). Scand. f. clin. Lab. Invest., 15,
Brown, C. J., and Stalker, A. L. (1968). Proceedings of the International Conference on Microcirculation, Gothenburg, Sweden, 1968. Gothenburg, Sweden.

Cash, J. D. (1966). Brit. med. F., 2, 502.

Cash, J. D., and Leask, E. (1967). Ұ. clin. Path., 20, 209.

Chesley, L. C., and Chesley, E. R. (1939). Amer. F. Physiol., 127, 731.

Das, P. C., Allan, A. G. E., Woodfield, D. G., and Cash, J. D. (1967). Brit. med. F., 4, 718.

Das, P. C., and Cash, J. D. (1968). In preparation.

Devi, B., Jennison, R. F., and Langley, F. A. (1968). F. clin. Path., 21, , B2.,

Ellis, B. C., and Stransky, A. (1961). F. Lab. clin. Med., 58, 477.

El-Mahallawi, M. N., Seif El-Din, D., Mahran, M., Sabour, M. S., and Fadel, H. E. (1968). Obstet. and Gynec., 31, 621.

Fearnley, G. R. (1953). Nature (Lond.), 172, 544 .

Gans, H., and Lowman, J. T. (1967). Blood, 29, 526.

Gillman, T., Naidoo, S. S., and Hathorn, M. (1959). Lancet, 2, 70.

Ginsburg, J., and Duncan, S. L. B. (1967). Cardiovasc. Res., 1, 132.

Gitlin, D., Landing, B. H., and Whipple, A. (1953). ₹. exp. Med., 97, 163.

Hammond, J. D S., and Verel, D. (1959). Brit. F. Haemat., 5, 431.

Herschlein, H. J., and Steichele, D. F. (1968). Thrombos. Diathes. haemorrh. (Stuttg.), 19, 248.

Huckabee, W. E. (1962). Amer. F. Obstet. Gynec., 84, 1623.

Hytten, F. E., and Leitch, I. (1964). The Physiology of Human Pregnancy. Oxford.
Kawano, T., Morimoto, K., and Uemuld, Y. (1968). Nature (Lond.), $217,253$.

Lewis, J. H., Ferguson, E. E., and Schonfeld, C. (1961). F. Lab. clin. Med. 58, 247.

Mackay, A. V. P., Das, P. C., Myerscough, P. R., and Cash, J. D. (1967). F. clin. Path., 20, 227.

McKay, D. G., Margaretten, W., and Rothenberg, J. (1964). Lab. Invest., 13, 54.

McLennan, C. E. (1943). Amer. 7. Obstet. Gynec., 45, 568.

Merskey, C., Kleiner, G. J., and Johnson, A. J. (1966). Blood, 28, 1.

Metcalfe, J., Romney, S. L., Ramsey, L. H., Reid, D. E., and Burwell, C. S. (1955). F clin. Invest., 34, 1632.

Murakami, M. (1965). Fap. 7. clin. Path., 13, 542.

Naeye, R. L. (1961). New Engl. 7. Med., 265; 867.

Niléhn, J. E., and Nilsson, I. M. (1964). Scand. F. Haemat., 1, 313.

Nilsson, I. M., Krook, H., Sternby, N.-H., Söderberg, E., and Söderström, N. (1961). Acta med. scand., 169, 323.

Nilsson, I. M., and Kullander, S. (1967). Acta obstet. gynec. scand., 46, 273.

Olesen, E. S. (1961). Scand. 7. clin. Lab. Invest., 13, 410.

Ratnof, O. D. and Menzie, C. (1951). 7. Lab. clin. Med., 37, 316.

Seitchik, J. (1967). Amer. F. Obstet. Gynec., 97, 701.

Shaper, A. G., Kear, J., Macintosh, D. M., and Kyobe, J. (1965). F. Obstet. Gynaec. Brit. Cwlth, 75, 433.

Shaper, A. G., Macintosh, D. M., Evans, C. M., and Kyobe, J. (1965). Lancet, 2, 706.

Sherry, S., Fletcher, A. P., and Alkjaersig, N. (1959). Physiol. Rev., 39, 343.

Simcock, M. J., and Forster, F. M. C. (1967). Med. F. Aust., 2, 971.

Turpie, A. G. G., Forbes, C. D., and McNicol, G. P. (1967). Brit. med. F., 3, 646 .

Winner, W. (1965), Obstet. gynec. Surv., 20, 545.

Woodfield, D. G., Cole, S. K., and Cash, J. D. (1968). Amer. F. Obstet. Gynec., 102, 440 .

Woodrow, J. C., and Finn, R. (1966). Brit. F. Haemat., 12, 297.

Wright, H. P., Osborn, S. B., and Edmonds, D. G. (1950). Surg. Gynec. Obstet., 90, 481 .

\title{
Hypercalciuria Relative to Total Solutes in Nephrolithiasis
}

\author{
L. C. ISAACSON, ${ }^{*}$ M.D., PH.D., M.R.C.P.ED.
}

Summary : Urines obtained from normal controls, from patients with calcium-containing renal stones, and from acutely ill patients suffering from various other renal or electrolyte disorders were analysed for $\mathrm{Na}, \mathrm{K}, \mathrm{NH}_{4}$, $\mathrm{Ca}, \mathrm{Mg}$, inorganic phosphate and sulphate, $\mathrm{pH}$, and osmolality.

The stone-formers' urines were found to be characterized by hypercalciuria relative to $\mathrm{Na}, \mathrm{K}, \mathrm{Mg}, \mathrm{SO}_{4}$, osmolality, and ionic strength. Hypercalciuria relative to osmolality was a more consistent finding than hypercalciuria relative to $\mathrm{Na}$.

These findings are in keeping with the supposition that calcium-containing renal stones occur in urine saturated with calcium salts.

\section{Introduction}

Hypercalciuria, relative to osmolality, characterizes the urines of patients with calcific nephrolithiasis (Isaacson, Modlin, and Jackson, 1966 ; Chambers and Dormandy, 1967). Hypercalciuria relative to sodium also characterizes these urines (Modlin, 1967). As $\mathrm{NaCl}$ normally contributes substantially to the urinary osmolality, it is not clear which is the primary feature: hypercalciuria relative to all the urinary solutes or hypercalciuria relative essentially to $\mathrm{Na}$ alone.

Light can be thrown on this problem by comparison of stone-formers' urines, not with those of normal subjects in

* Endocrine-Metabolic Research Group, Department of Medicine, University of Cape Town. Present address : Department of Physiology, University of Cape Town. which $\mathrm{Na}$ and osmolar concentrations are usually highly correlated, but rather with those of a non-stone-forming population in which these concentrations are not correlated. Differentiation of the stone-formers' urines from those of this population will then be best accomplished by whichever of these indices ( $\mathrm{Ca} /$ osmolar or $\mathrm{Ca} / \mathrm{Na}$ ratio) is the more fundamental.

Acutely ill patients suffering from a variety of renal or electrolyte disorders (but not with renal stones) constitute such a population. Comparison of their urines with those of patients with calcium-containing renal stones shows that hypercalciuria relative to the total solutes, rather than to $\mathrm{Na}$ alone, is the primary feature characterizing the urines of patients with nephrolithiasis.

\section{Methods}

Random urine samples were obtained from 42 normal individuals and from 50 acutely ill patients in hospital. The sole criterion for selection of these patients was that they suffered from renal or electrolyte disorders, and did not have renal stones. These patients have been briefly reported on, and their various diagnoses listed, in an earlier report (Isaacson et al., 1966).

In addition 24-hour urines were collected from 21 patients with calcium-containing renal stones. None of these subjects was acutely ill, nor did they have any of the conditions known to predispose to renal stone formation.

All urines were collected under toluene and stored at $4^{\circ} \mathrm{C}$. while awaiting analysis. The volume of each 24-hour aliquot was measured. Each urine was analysed for $\mathrm{pH}, \mathrm{Na}, \mathrm{K}, \mathrm{NH}_{4}$, 